\title{
Comparative Sequence Analysis of Genes Encoding Outer Proteins of African Swine Fever Virus Isolates from Different Regions of Russian Federation and Armenia
}

\author{
Natalia N. Vlasova ${ }^{1, *}$, Anna S. Kazakova ${ }^{1}$, Alis a A. Vare ntsova ${ }^{1}$, Tatyana A. Akopian ${ }^{2}$, \\ Ele na S. Kostryukova ${ }^{2}$ \\ ${ }^{1}$ Russian Academy of Agricultural Sciences, State Research Institution National Research Institute for Veterinary Virology and Microbi- \\ ology of Russia (SRI NRIVV\&MR), Pokrov, 601120, Russia \\ ${ }^{2}$ Federal Medical-Biologycal A gency, Federal State Institution Science Research Institute for Phy sical-Chemical Medicine (FSI SRIPCM), \\ Moscow, 119435, Russia

\begin{abstract}
African swine fever (ASF) is an economically important disease of domestic pigs. ASF is endemic in most of sub-Saharan Africa, including Madagascar Island; the highest incidence of disease being recorded from the West and East Africa to the Southern Africa. Disease outbreaks have also occurred in Europe, South America and the Caribbean. In 2007 it was introduced into Georgia, and has since spread throughout the Caucasus and into southern Russia. There is no vaccine or treatment available to control ASF v irus. There fore time ly ASFV detection and characterization are crit ical to understand and contain its spread. In this report, we describe the nucleotide structure analysis of genes E183L, KP177R and O61R encoding for proteins p54, p22 and p12, respectively, for different ASFV isolates collected within three years from South European regions of Russia and Armenia. The comparative analysis of these demonstrated variability in p12 sequences of the isolates from different geographic regions and hosts, whereas p54 and p22 sequences were conserved among the isolates. However, hydropathy profile analyses did not reveal any structural variations for all three proteins. It suggests that $\mathrm{p} 12$ genes, but not p54 and p22 genes, is under strong selective pressure and can be a valuable geno mic marker for studying of evolutionary pathways and genetic diversity of ASFV isolates.
\end{abstract}

Keywords African Swine Fever Virus, P54 Gene, P22 Gene, P12 Gene, Hydropathy Profile, Phylogenetic Analysis, Comparative Sequence Analysis

\section{Introduction}

The causative agent of African swine fever (ASF) is a large desoxyribovirus that has been assigned to Asfarviridae family[1]. Dixon L.K. et al. noted, that although initially ASFV was classified as an Iridovirus based largely on virion morphology, increasing molecular biological data led to its reclassification as the sole member of a new DNA virus family, Asfarviridae (A s f a $\mathrm{r}$ - A frican swine fever and related viruses). African swine fever virus (ASFV) replicates in cytoplasm and has variable virulence to domestic pigs, with infections ranging from $h$ ighly lethal to subclinical. ASFV genes encoding proteins which modulate host immune response, viral virulence to domestic swine, and the ability of ASFV to replicate and spread in its tick vector. ASFV is the only known DNA-arbovirus.

Domestic and wild pigs are susceptible. African bush pigs

* Corresponding author:

vlanany@yandex.ru (Natalia N. Vlasova)

Published online at http://journal.sapub.org/ijvmb

Copyright (C) 2012 Scientific \& Academic Publishing. All Rights Reserved and warthogs infected with ASFV are generally asymptomatic, with low level viremia. ASFV persistently infects ticks of the genus Ornithodoros from which ASFV can be isolated 5-10 years post infection[2]. ASFV infection of domestic swine results in several disease forms, ranging from highly lethal to subclinical depending on contributing viral and host factors. African swine fever is characterized by oedemas, ascites and haemorrhages, virus replication and spread within mononuclear-macrophage system, long-term carrier state, nonvirulent strains of virus induce latent infection.

Its virion diameter is $\sim 200 \mathrm{~nm}$, contains more than 50 proteins and consists of several concentric layers enclosing an electron-dense nucleoid, containing a double stranded DNA genome of approximately 190 kilobase pairs (kbp). The core is enwrapped by an inner lipid envelope that lies beneath the icosahedral capsid[3, 4]. Extracellular particles possess an additional envelope derived from the plasma membrane[4].

Analyses of cell extracts revealed the presence of more than 100 viral proteins synthesized on different phases of ASFV life cycle[5-6]. ASFV p54 is an externally located 
viral structural protein of $25-27 \mathrm{kDa}$, encoded by the virus gene - the open reading frame (ORF) E1 83L[7-8].

ASFV protein $\mathrm{p} 54$ is involved in the adsorption of the virion on susceptible cells and the early steps of viral infection[9].

Published data have shown that ASFV p54, p30, p22 and p12 are essential virus proteins involved in early events of the replication[10,11].

The protein encoded by the gene - ORF KP177R, is an early structural protein of apparent molecu lar we ight $22 \mathrm{kDa}$, located externally in the viral particle. The protein contains a hydrophobic region at the $\mathrm{N}$-terminus with the characteristics of a signal peptide and seems to appear transiently in the plas ma me mb rane early after ASF v irus infection[12].

The ASFV virus protein p12 (ORF O61R) is involved in virus attachment to the host cell and located within the outer envelope of the virions. This protein is not synthesized during early phases of infection and undergoes post trans lational modification[13]. The protein $\mathrm{p} 12$ has trans-membrane domain and cysteine-rich region which is responsible for the dimerization at the $\mathrm{C}$-tail.

Multimers of the protein with an apparent molecular mass of $17 \mathrm{kDa}$ in the absence of 2-mercaptoethanolwere detected. Labelling experiments with[35S] methionine and immunoprecipitation with specific antibodies directed against protein p12 indicated that the gene is expressed during the infection of swine macrophages with all of the viruses tested. The nucleotide sequence of a DNA frag ment containing the gene encoding for protein $\mathrm{p} 12$ in several virus strains has shown that the $5^{\prime}$ flanking region is conserved in all the virus isolates sequenced, whereas the intergenic region downstream of the gene varies among different isolates[14].

Currently, there is no vaccine available against ASF and the disease is controlled by animal quarantine and slaughter. It is believed that the lack of efficient ASFV vaccines might be due to unique molecular and biological properties of ASFV proteins responsible for virus-cell interactions: $\mathrm{p} 54$, $\mathrm{p} 22$ and $\mathrm{p} 12$.

It is believed that extensive studies of ASFV structure, genes, immune mechanis ms which affect viral replication, virus-host interactions, and virulence will help to effectively control this dangerous agent.

This article is devoted to the investigation of the nucleotide structure of genes encoding outer proteins p54, p 22 and p12 of African swine fever virus isolates from the different regions of Russian Federation and Armenia.

\section{Material and Methods}

\subsection{Cells and Viruses}

Primary porcine blood macrophage cell (PBMC) or leucocyte cultures were prepared from swine blood. Briefly, heparin-treated swine blood was incubated at $37^{\circ} \mathrm{C}$ for $1 \mathrm{~h}$ to allow sedimentation of the erythrocyte fraction. Mononuclear leukocytes were separated by flotation over a $\mathrm{Fi}$ coll-Paque (Pharmacia). The monocyte-macrophage cell fraction was cultured in Dulbecco's modified Eagle's medium containing 5\% fetal bovine serum (FBS, Sig ma)[15].

The virulent ASFV isolates Krasnodar 2008 (domestic pigs), Elbrus 2008 (wild boar), Stavropol 2008 (domestic pigs), Orenburg 2009 (domestic pigs), Rostov 2009 (domestic pigs), Volgograd 2010 (wild boar) and Armen ia 2007 (domestic pigs) were obtained in 2007-2011. These ASFV isolates were passaged no more than 2-5 times in leucocyte culture primary porcine blood macrophage cell cultures prior to DNA isolation, PCR-amplification and nucleotide sequencing.

\subsection{He mads or pti on (HAD) Test}

The hemadsorption test[16] is based on the ability of pig erythrocytes to adhere to the surface of pig monocyte or macrophage cells infected with ASFV. Three days old leucocyte culture in 96-well microplates was inoculated with 10 -fold dilutions $(200 \mu 1 /$ well $)$ of treated sterile sample of med ium or virus (at least four wells per dilution).

After that $20 \mu 1$ of freshly prepared $1 \%$ suspension of pig erythrocytes in the physiologic buffered solution (PBS) were added to each well. The inoculated cells were incubated at $37^{\circ}, 5 \% \mathrm{CO} 2$ during 7 days and the plates were checked for the presence of HAD.

\subsection{Constructing of p54, p22 and $\mathrm{p} 12$ Genes Containing Plas mi ds}

The amplification of these genes was carried out with the following primers:

p54: 5'-CTTATAATATACT GCA GTAT GTTGA GTC-3' and

5'-TTCTT GA GGATCCTTGGAAA GT TGGTCC-3'[1 7];

p22: 5'-CA GAAA GGATCCAATATTAT GTA GACC-3' and

5'-CGATGCA CAATATTATAAGCTTTAAACCG-3' [17];

p12: 5'-GCGGATCCTTGAATAAGCGTTAAC-3' and 5'-GCGGATCCGACATCATTATGGATGA-3'[14].

The DNA templates used for the amplification reactions were obtained either from peripheral blood of infected pigs, for the wild-type viruses, or from supernatants of ASFV infected cell cultures.

The DNA samples used in the PCR were heated at $95^{\circ} \mathrm{C}$ for $5 \mathrm{~min}$ before addition to the reaction mixture and PCR-amplification PCR fragments consisted of a single band that varied in size among the virus genes when analyzed by $1,5 \%$ agarose gel electrophoresis [14, 17]. PCR products were cloned into plas mids pTZ57R/T (Fermentas, Republic of Lithuania) and pAL-TA (ZAO Evrogen, Russia)[18]. DNA samples, containing full size copies of genes encoding p54, p22 and p 12 (E183L, KP177R and O61R) were obtained by PCR amplification from purified DNA of different ASFV isolates using the specific primers. Recombinant clones were generated by inserting PCR-products of p54 genes and p22 genes into pTZ57R/T or PCR-p roducts of p12 genes into pAL-TA. DNA samples of recombinant plasmids, containing p54 genes, p22 genes and p 12 genes, were sequenced using the same primer pairs as for PCR. 
The sequences were obtained for at least two independent clones of each virus isolate.

\subsection{DNA Sequencing and Computer Analysis}

Cloned p54, p 22 and p 12 genes were sequenced by the dideoxynucleotide chain terminator method, according to standard procedures [19].

Comparative analysis of DNA sequences of E183L, $\mathrm{KP} 177 \mathrm{R}$ and O61R genes of different ASFV field isolates and strains was performed using the package Bio Ed it 6.0.

Nucleotide sequences of genes encoded p54 of different ASFV strains and isolates: LIS/57 (Accession number EU874321.1), TENGANI/62 (EU874318.1), MOZ/1979 (EU874372.1), $\quad$ E70 (FJ174389.1), OURT 88/3 (AM712240.1, protein id CAN10474.1), KEN/50 (EU874353.1), p22 - Tengani 62 (A Y261364.1), E75 (FN557520.1, protein_id CBH29101.1), OURT 88/3 (AM712240.1, protein_id CAN10352.1), KENYA 1950 (A Y261360.1) and p12 - LIS57 (M84178.1), TEN61 (M84177.1), E70(E75) (FN557520.1, protein_id CBH29198.1), OURT 88/3 (AM712240.1, protein_id CAN10447.1), KENYA 1950 (A Y261360.1), KIR69 (M84183.1) deposited in GenBank were used. The sequences of Georg ia 2007/1 strain complete genome (Accession number FR682468.1) were used for analyses and for comparison as reference sequences of genes p54 (protein id CBW46791.1), p22 (protein_id CBW46645.1), p12 (protein_id CBW46764.1).

\subsection{Hydropathy Profiles}

Hydropathy profiles of ASFV proteins p54, p 22 and $\mathrm{p} 12$ were obtained following the procedure of Hoop \& Woods[20].

\subsection{Phylogenetic Analysis}

Bio Edit 6.0 software packages was used for the phylogenetic analysis. Phylogenetic trees were constructed using neighbour-joining algorithm[21]. A 603 bp, 534 bp, 138 bp frag ments were used to construct phylogenetic trees for $\mathrm{p} 54$, p22 and p 12 genes, respectively.

\section{Results}

\subsection{He mads or pti on Test}

ASFV protein $\mathrm{CD} 2 \mathrm{v}$ is responsible for the attachment of erythrocytes to infected cells and this ASF' virus protein is the most variable protein[22, 23]; we examined all Russian isolates for the presence of the phenomenon hemadsorption during their reproduction.

HAD analyses demonstrated that all tested ASFV isolates from different regions of Russian Federation and Armenia (Krasnodar 2008, Elbrus 2008, Stavropol 2008, Orenburg 2009, Rostov 2009, Volgograd 2010 and Armenia 2007) produced phenomenon of hemadsorption (Figure 1).

Since the character of hemadsorption during the virus reproduction with these isolates was identical, indicating a reasonable stability of the gene structure, we considered it is not necessary to analyze the gene encoding this protein.
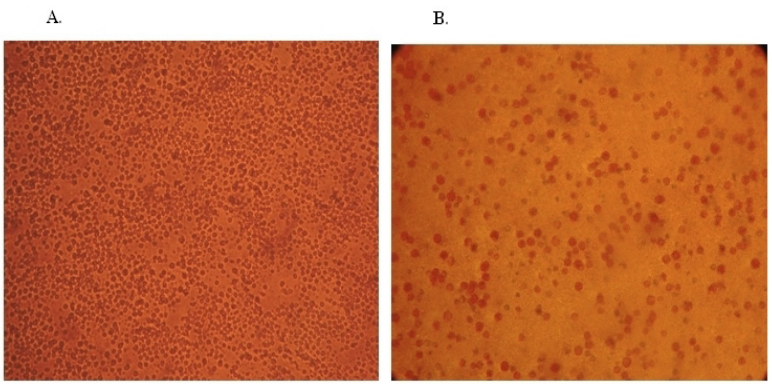

Figure 1. HAD test of Russian ASFV isolates from different regions in leukocyte cultures: A. The 3-days old leukocyte culture; B. The hemadsorption phenomenon produced by ASFV (Rostov 2009 isolate) in the leukocyte culture - 4 days post inoculation

\subsection{Molecular Cloning and Sequencing of p54, p22 and p12 Genes}

The results of sequencing and gene mapping with specific primers localization revealed that the ORF E183L (p54) located within nucleotide (nt) 162222-162776 of Georgia 2007/1 isolate genome. The rightwards transcribed ORFs coding p12 and p22 located within 128803-128988 nt and 3212-3781 nt, correspondingly (Fig. 2).

Therefore, the ORF E183L locates at the 5' end negative-chain DNA of the Georgia 2007/1 isolate genome (162222-162776 nt) and codes for a late induced structural glycoprotein p54 of $25 \mathrm{kDa}$ (Fig. 2).

The ORF KP177R locates at the 5' end of the positive-chain DNA of Georgia 2007/1 isolate genome (3212 $-3781 \mathrm{nt}$ ) and codes for an early induced external viral structural protein $\mathrm{p} 22$ of $22 \mathrm{kDa}$ (Fig. 2)

The ORF O61R locates at the positive-chain DNA central left part of Georgia 2007/1 isolate genome (128803-128988 $\mathrm{nt}$ ) and codes for an early induced structural protein $\mathrm{p} 12$ of $12 \mathrm{kDa}$ (Fig. 2).

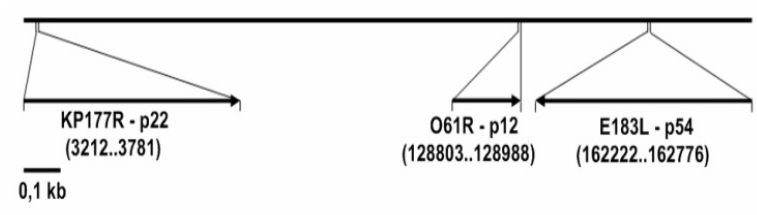

Figure 2. Positions of the E183L, KP177R and O61R ORFs on the genome map of African swine fever virus isolate Georgia 2007/1; size of complete genome $\sim 189344 \mathrm{bp}$. The arrows indicate direction of the gene transcription and figures show positions of the genes

Nucleotide sequencing of the gene structure encoding of p54 was identical for six different viral isolates: Krasnodar 2008, Elbrus 2008, Stavropol 2008, Orenburg 2009, Rostov 2009 and Armenia 2007 (Figure 3, only Armenia 2007 and Stavropol 2008 sequences are shown).

Nucleotide sequence of same Georgia 2007/1 gene demonstrated a single nucleotide substitution from Russian isolates - within $438 \mathrm{nt}$ (Figure 3).

African ASFV isolates had lower the p54 gene nucleotide sequence identity with that of European and American iso- 
lates, indicating greater nucleotide heterogeneity among common origin for non-African isolates[24]. viruses from different geographic regions and indicating a

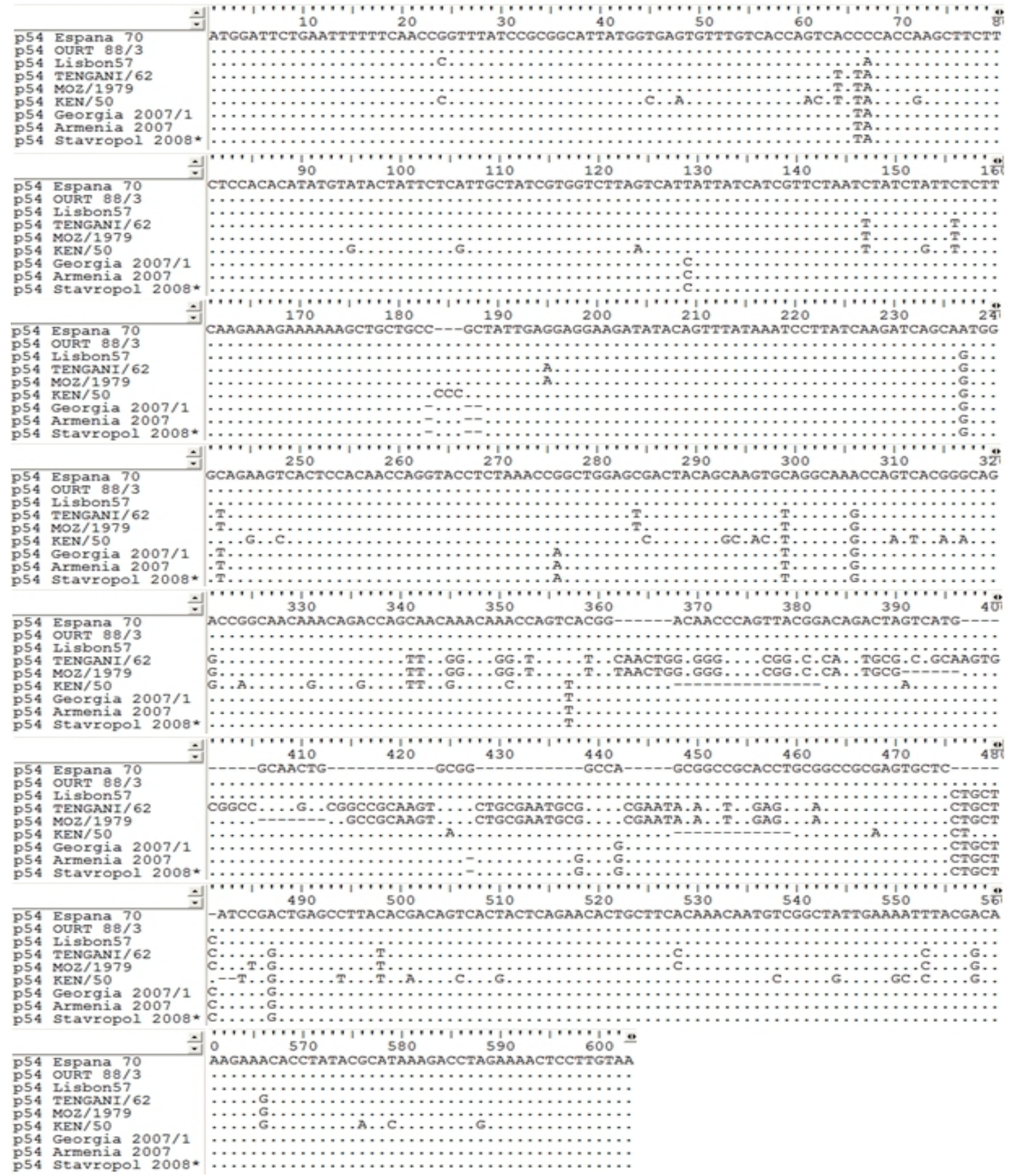

Figure 3. Multiple alignment of the p54 gene nucleotide sequences of ASFV isolates: • (point) - indicates identical nucleotide; - (dash) - indicates absence of nucleotide; *(asterisk) - indicates identical sequences of Krasnodar 2008, Elbrus 2008 and Orenburg 2009, Rost ov 2009 E183L gene 


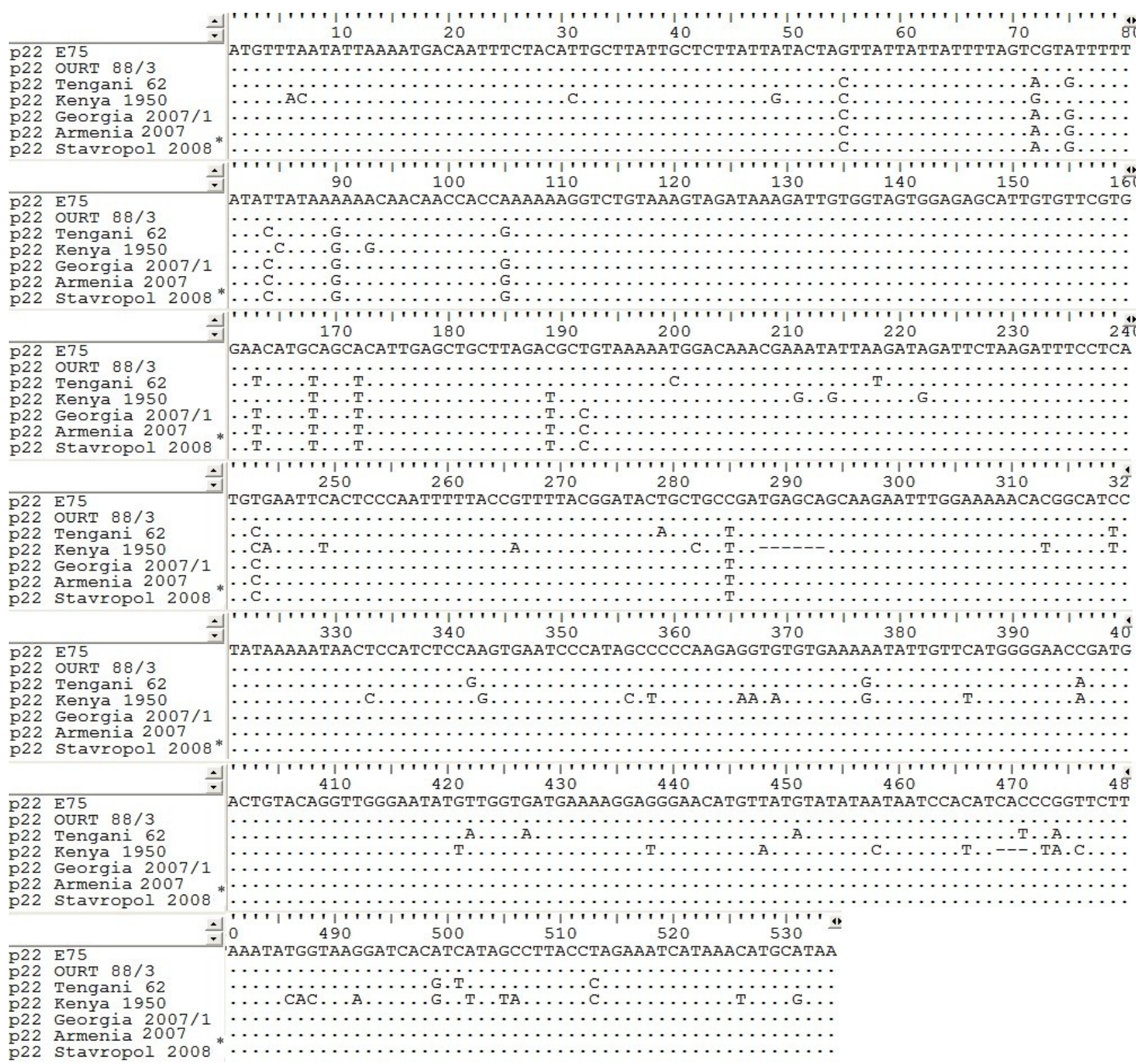

Figure 4. Multiple alignment of the p22 gene nucleotide sequences of ASFV isolates: • (point) - indicates identical nucleotide; - (dash) - indicates absence of nucleotide; *(asterisk) - indicates identical sequences of Krasnodar 2008, Elbrus 2008 and Orenburg 2009, Rostov 2009 KP 177R gene

Nucleotide sequence structure of the p22 gene was also identical for six different $v$ iral isolates from Rostov, Krasnodar, Elbrus, Stavropol, Orenburg, Armenia as well as Georgia. The p22 gene Kenya 1950 gene had maximal nucleotide substitutions of 9 strains compared (Figure 4, only Armenia 2007 and Stavropol 2008 sequences are shown). Thirteen nucleotide substitutions were recognized in ASFV Georgia 2007/1 and Russian isolates' the p22 gene sequences which were not found in E 75 strain genome. Also, 51 nucleotide substitutions were identified in ASFV Kenya 1950 genome, which were not found in Georg ian, Armenian and Russian isolates genome sequences (Figure 4).

We analysed the variability of the gene, encoding protein p12 by comparing the sequences of 5 field virus isolates: Elbrus 2008, Stavropol 2008, Orenburg 2009, Volgograd 2010 and Armenia 2007.
The nucleotide sequence of the p12 gene of different ASFV isolates showed variability within regions from 195 to 248 and from 296 to 320 nucleotides (Figure 5).

We identified a 28nt-long insertion in $\mathrm{p} 12$ gene of Georgia 2007/1, Elbrus 2008, Stavropol 2008, Orenburg 2009, Volgograd 2010 and Armenia 2007 isolates (nt 218-245) which was absent in other European strain gene sequences with the exception of African - Kiravira 69, Tengani 61 and Kenya 1950 genes containing less than $28 \mathrm{nt}$ insertions in the same region (Figure 5).

A few mutations in the sequence of $\mathrm{p} 12$ gene were observed between 170 to 265 nucleotides when different isolates were compared, whereas identical sequences were found when European group isolates were analysed (Lisbon 57, Espana 70 and OURT 88/3) (Figure 5). 


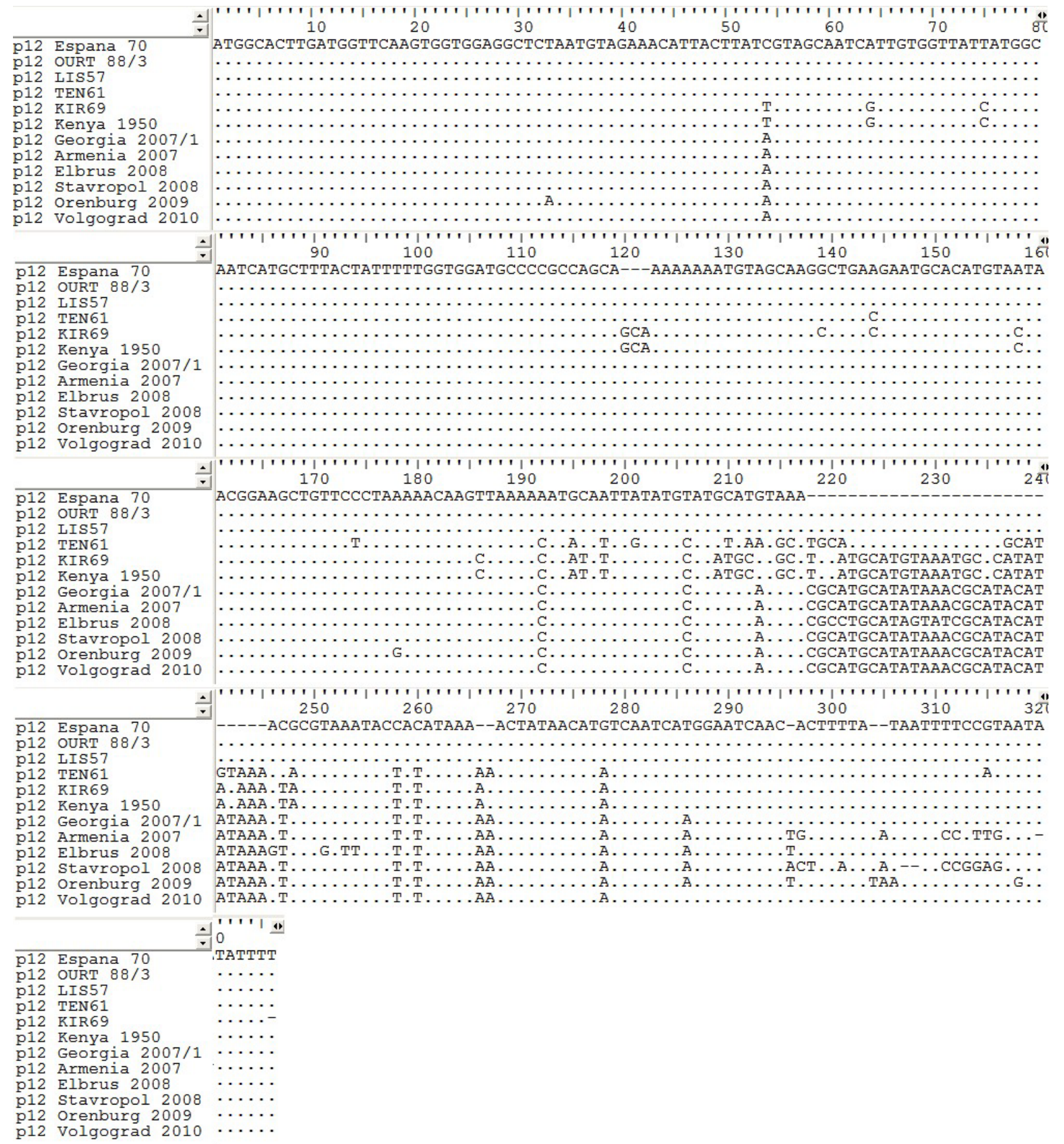

Figure 5. Multiple alignment of the PCR-product p12 gene nucleotide sequences of ASFV isolates: (point) - indicates identical nucleotide; - (dash) indicat es absence of nucleotide

\subsection{Hydropathy Analysis}

Since we found single nucleotide substitutions in the p22 and $\mathrm{p} 12$ genes, and for the $\mathrm{p} 12$ gene nucleotide substitution occurred at the $\mathrm{N}$-terminus with a net positive charge. It was necessary to check to see whether they affect the functional properties of encoded by these genes proteins. Hydropathy analysis makes possible recognition of protein function modifications when respective gene sequences vary. It was performed by using predicted amino acid sequences of ASFV p 54, p22 and $\mathrm{p} 12$ proteins.

The hydrophilicity profile of p54 (Figure 6) revealed the presence of a highly hydrophobic stretch, formed by 37 amino acid residues (a.a.) of p54 and a long hydrophilic C-terminus formed by 130 a.a. residues.

There was also a highly hydrophobic stretch, consisted of 26 amino acid residues and a long hydrophilic C-terminus formed by 140 a.a. residues in hydrophilicity profile of $\mathrm{p} 22$ (Figure 7).

Since nucleotide sequences of p54 genes were identical for six different viral strains - Krasnodar 2008, Elbrus 2008, Stavropol 2008, Orenburg 2009, Rostov 2009 and Armenia 2007 -we did not expect any differences in the functions of respective protein. 


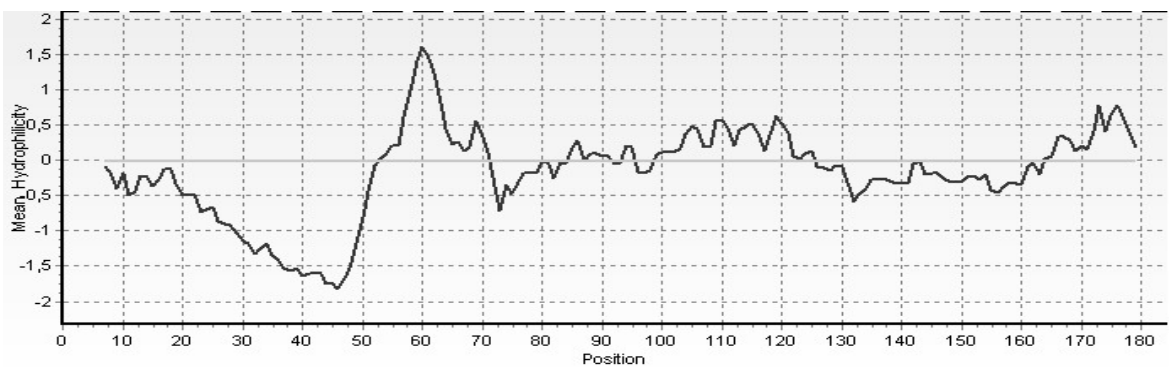

MDSEFFQPVYPRHYGECLSPVTTPSFFSTHMYTILIAIVVLVIIIIVLIYLFSSRKKKAAAIE EEDIQFINPYQDQQWVEVTPQPGTSKPAGATTASVGKPVTGRPATNRPATNKPVTD NPVTDRLVNATGGPAAAPAAASAPAHPAEPYTTVTTQNTASQTMSAIENLRQRNT YTHKDLENSL *

Figure 6. The Hoop \& Woods scale mean hydrophilicity profile of Stavropol 2008 ASFV isolate p54 protein: the hydrophilic N-terminal domain formed by 20 residues is underlined; the boxed region corresponds to the hydrophobic stretch of 37 amino acid residues near the $\mathrm{N}$-terminus of the polypeptide (residues 22 to 58); bold font corresponds to the hydrophilic C-terminus formed by 130 amino acid residues

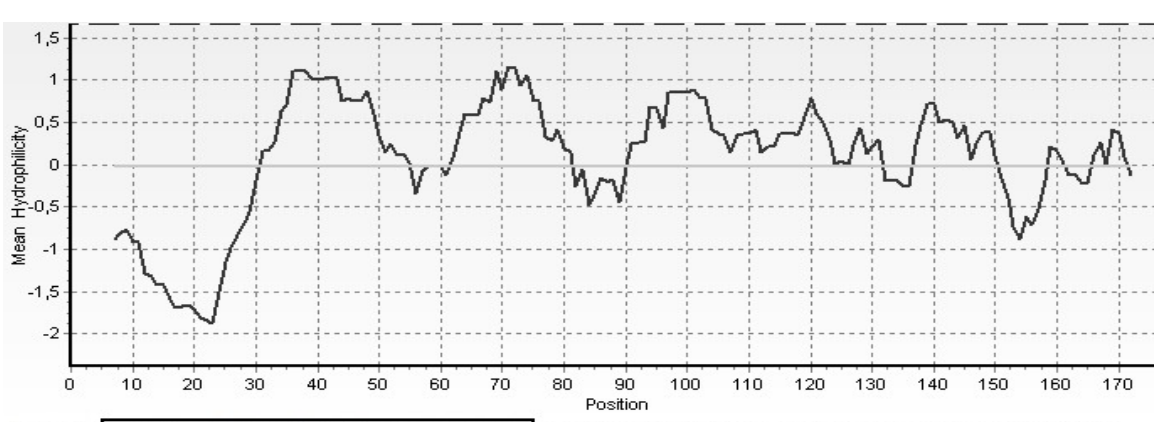

MFNIK MTISTLLIALIILLIIILVVFLYYKKQQPPKKVCKVDKDCGSGEHCVRGSCSSLS

CLDAVKMDKRNIKIDSKISSCEFTPNFYRFTDTAADEQQEFGKTRHPIKITPSPSESH

SPQEVCEKYCSWGTDDCTGWEYVGDEKEGTCYVYNNPHHPVLKYGKDHIIALPR

NHKHA*

Figure 7. The Hoop \& Woods scale mean hydrophilicity profile of Stavropol 2008 ASFV isolate p22 protein: five amino acids (positions 1 to 5 ) at the $\mathrm{N}$-terminus with a net positive charge are underlined; the boxed region corresponds to a hydrophobic stretch of 26 amino acid (positions 6-31); bold font corresponds to the long hydrophilic C-terminus formed by 140 amino acid residues

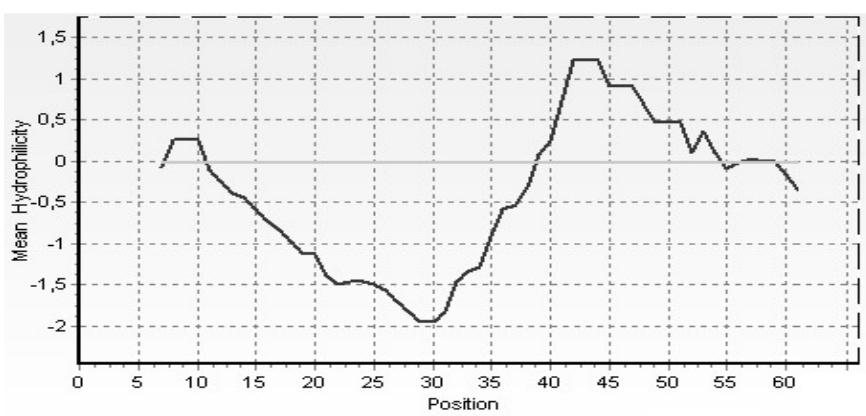

\section{MALDGSSGG SNVETLLIVAIIVVIMAIML YYFWWMPRQQKKCSKAEECTCNNGSC}

Figure 8. The Hoop \& Woods scale mean hydrophilcity profile of Orenburg 2009 ASFV isolate p 12 protein: ten amino acids (positions 1 to 10 ) at the $\mathrm{N}$-terminus with anet posit ive charge are underlined; the boxed region corresponds to the hydrophobic stretch of 30 amino acid residues near the N-terminus of the polypeptide (residues 11 to 48 ); bold font corresponds to the short hydrophilic C-terminus formed by 13 amino acid residues

The deduced amino acid sequences of the p12 shows a stretch of 22 hydrophobic residues that functions as to anchor the protein in the external virus envelope. A hydrophilic C-terminus formed by 13 a.a. residues (Figure 8).

Despite few mutations present in the sequences of $\mathrm{p} 12$ gene of Russian and Armenian isolates within regions from 195 to 248 and from 296 to 320 nucleotides, we did not observe changes of the structure hydrophobic trans membrane segment, the hydrophilic $\mathrm{C}$-terminus formed by 13 a.a. residues.

\subsection{Phylogenetic Analysis of AS FV Isolates}

The nucleotide sequences of orthologous genes from seven ASFV isolates (Armenia 2007, Krasnodar 2008, Elbrus 2008, Stavropol 2008, Orenburg 2009, Rostov 2009 and Volgograd 2010) were analysed and phylogenetic trees were constructed for the genes encoding p54, p22 and p12.

The p54 gene-based neighbour-joining tree demonstrated that Russian isolates together with Georg ia 2007/1 isolate form a separate clade with in the Eu ropean cluster. The other cluster comprises Southern African isolates - Tengani and Mozambique (Figure 9a).

The p22 gene phylogenetic analysis demonstrated that Russian isolates and Georgia 2007/1 isolate cluster together 
and are closer related to European isolates than to Southern African isolates (Figure 9b).

All Russian and Armenian isolates had specific mutations in O61R gene. The phylogenetic analysis for $\mathrm{p} 12$ gene also demonstrated that Russian isolates and Armenia 2007 isolate formed a group separate from European and African isolates. Within this group Russian and Armenian isolates formed several subgroups with Stavropol and Armenia closest to each other and Elbrus, Orenburg and Georg ia sharing higher homology with each other (Figure 9c). While Volgograd 2010 isolate formed another subgroup of its own.

Overall, Stavropolian and Armenian isolates share high homology between each other and with Georgia isolate suggesting that all Russian isolates may share a common origin with Georgia.
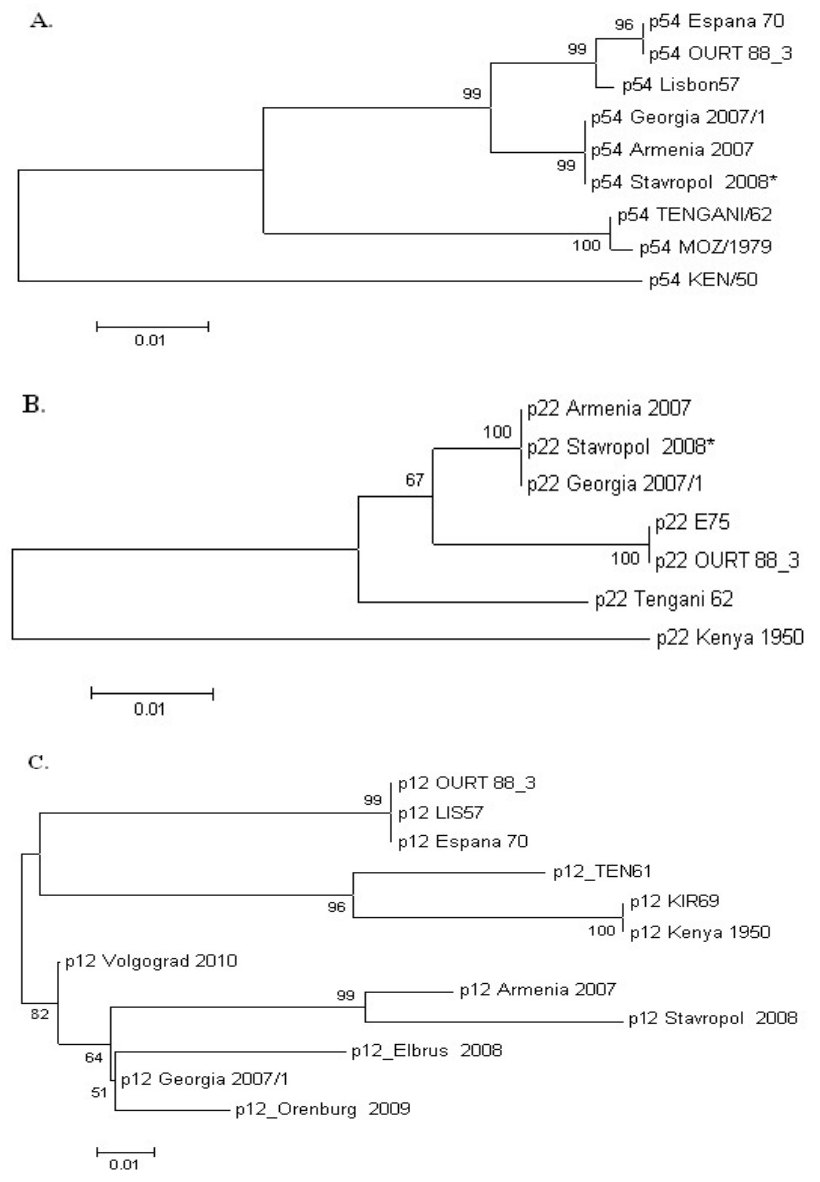

Figure 9. Neighbour-joining phylogenet ic trees of E183L (p54) gene (a), KP177R (p22) gene (b) and intergenic region of p12 gene (c) sequences of some representative ASFV isolatestested

\section{Discussion}

The ASFV genome contains discrete variable regions and elements, which were evident through restriction mapping[25] and comparative sequences' analysis. ASFV isolates and cell culture-adapted viruses contain a conserved, centrally located $125-\mathrm{kbp}$ genomic core in which major insertion-deletion events are rare, leaving larger-scale variability confined to the left 38 - to $47-\mathrm{kbp}$ and right $13-$ to 16-kbp terminal regions of the ASFV genome[26-28]. Rock D.L. [29] demonstrated that structure heterogeneity of 72 gene is no more than $10 \%$, while for CD2v- $40 \%$, p $54-30 \%$, p22 - 20\% and Angulo A. et al.[14] described structure heterogeneity of 12 gene about $35 \%$.

Previous results of Carrascosa A.L. et.al. showed that the deduced amino acid sequence of $\mathrm{p} 12$ protein included a trans-me mbrane do ma in, cysteine rich C-terminal region and a stretch of 22 hydrophobic residues, which functions as to anchor the protein in the external virus envelope[4]. The absence of cleavable N-terminal signal sequences in the predicted amino acid sequence of $\mathrm{p} 12$ protein suggests that the polypeptide is inserted into the membrane through the mechanis $\mathrm{m}$, which has been proposed for other proteins of low mo lecular mass[30].

The hydropathy profile of $\mathrm{p} 54$ reveals the presence of a very hydrophobic stretch, formed by 21 a mino acid residues, within the N-terminal region (residues 33 to 53) of the protein, which most likely represents a transmembrane domain[31].

The analyses of hydropathy profile allows to determine the functional properties of protein structure[32], in our case hydropathy profile of ASFV proteins p54, p 22 and $\mathrm{p} 12$ corresponded to the results of a similar analysis for those proteins, but did not show significant differences of their structures.

We observed that the ASF virus, which has a high degree of variability, changes in the process of passaging in vivo. Prior to phenotypic changes, ASFV isolates accumulate silent genomic mutations specific for different isolates[33]. Therefore, we chose the outer ASFV proteins that are under selective pressure and involved in the processes of attachment and penetration into the cell.

Bastos A.D. et al.[34] analyzed strains of African swine fever virus from different geographic zones by partial $\mathrm{p} 72$ gene characterization and the phylogenetic analyses. Genotyping distributed all ASFV isolates to 10 clusters: genotype I included all European strains and some isolates fro $m$ West Africa (from Angola to Senegal). Remaining 9 genotypes come from South, Central and East Africa and Madagascar.

The present genotyping strategy includes a two-step genetic characterisation approach whereby $\mathrm{p} 72$ gene sequencing is used to delineate genotypes, prior to intra-genotypic resolution of viral relationships by central variable region (CVR) characterisation of the 9RL ORF classify the ASFV isolates relative into the 22 currently known genotypes [35].

Malogolovkin A. et.al.[36] co mpared sequences of genes encoding p72 and showed that gene B646L of all Russian isolates was highly conserved with no substitutions.

The serotype-based classification of ASFV strains previously developed by Balyshev V.et al.[37] distributed all ASFV strains in ten groups including eight serotype-based groups, one group of non-serotyped strains and one group consisting of heterogeneous isolates. This classification characterizes strains into different seroimmunotypes based on the results of in vivo the cross-challenge and in vitro the hemadsorption inhibition test[38]. We found out that the 
immunodominant ASFV p54 is one of the virus proteins responsible for serotype specific ity[24].

Phylogenetic analys is based on gene p54 conducted earlier in our laboratory allowed to divide all tested ASFV strains and isolates into 8 groups consistent with serotype-based classification[24]. All Russian, Georgian and Armenian isolates belonged to VIII seroimmunotype together with Rhodesia 1984 strain. Comparative sequence analys is of p54 genes of these is olates showed that they were identical, thus, we concluded that the isolates belonging to the same serotype have identical genes encoding p54.

Earlier data of Angulo A. et al.[14] demonstrated that the p12 5'-flanking region sequence was conserved among the isolates, whereas sequences downstream of this gene were highly variable in length and contained direct repeats in tandem. However, the main properties of the p12 protein were not altered in the original isolates and viruses adapted to grow in established cell lines. As noted by Angulo A., et al.[39], there is no correlation between the length of this sequence and any of the properties of these viruses, such as pathogenicity or capacity to grow in different cell types.

Rowlands R.J. et.al.[39] obtained sequences of 4 regions of ASFV genome, including B646L (p72), E183L (p54), CP204L (p30) and B602L (CAP80). Phylogenetic analyses of this four genes showed that Georgia 2007/1 isolate belonged to genotype II, which circulated in Zambia, Mozambique and Madagascar. Our results are consistent with data of Rowlands R.J. et.a1.[40]: Krasnodar 2008, Elbrus 2008, Stavropol 2008, Orenburg 2009, Rostov 2009, Armenia 2007 is olates belonged to genotype II.

The phylogenetic analysis of 123 concatenated genes separated the viruses into two major clusters that correlate with their geographical distribution[41].

Gallardo C. et.al. compared sequences of genes encoding p72, p54, p30 and central variable region (CVR) to increase resolution of additional loci and to study geographic distribution of ASFV isolates[42]. The CVR within the ORF B602L had been found to be the most useful locus for differentiation of closely related isolates and identification of p72-based virus subgroups.

Subsequent analysis of the genetic relatedness of Russian and Armenian ASFV isolates based on p12 gene intergenic region demonstrated some differences: Russian and Armenian isolates originate from Georgia, but contained 9 different nucleotide substitutions and 5 insertions.

\section{Conclusions}

Our assumption that the gene p12 (in particular, its intergenic region) analysis can provide reliable information about the phylogenetic relationship between different isolates was fully confirmed in this study phylogenetic and comparative sequence analyses. Between nucleotides 218 and 255 we found insertions typical for these isolates and Georgia 2007/1 strain. A characteristic feature of all investigated genomes of African isolates was the presence of the shorter insertions in the same region. Unfortunately, we did not find more information in Gene Bank and had no data on the sequences of the 12 gene for the Mozambique 1979 and Rhodesia 1984 isolates, which would allow us to exactly determine the feasibility of using phylogenetic analysis for the specified region of ASF virus genome. Nevertheless, our findings suggest there is a need to analyze this region, because we found differences in the isolates with different passage history and of different orig in.

The 12 based phylogenetic analysis allowed to define subgroups among Russian isolates while showed the same relatedness with European and African isolates as p22 and p54 based phylogenetic analyses.

The differences between 12 gene sequences may be reflective of different transmission pathways of the isolates. It is possible that the Volgograd 2010 isolated from a wild boar accumulated numerous genomic changes due to higher transmission rate in these hosts or that a diverse ASFV strain pool circulating in the wild boar population. While ASFV isolates from domestic pigs in Krasnodar, Stavropol and Orenburg reg ions are highly ho mologous between each other and their spread was likely mediated by humans.

Because our results have confirmed the stability of p54 genes in isolates belonging to one serotype, we can recommend analysis of this genomic region to identify changes in circulating virus' serotype, similar to that of long time epizootic in Spain and Portugal, when the virus I serotype was gradually supplanted by the IV serotype virus.

Overall, comparative analysis of the genes encoding p 54, $\mathrm{p} 22$ and $\mathrm{p} 12$ proteins presented in this study indicates that p 12 gene, but not p22 and p54 genes, is under strong selective pressure and can be a valuable genomic marker for studying of evolutionary pathways and genetic diversity of ASFV isolates.

\section{Nucleotide Sequence Accession Numbers}

The DNA sequence data in this report have been submitted to the Gen Bank data base under accession numbers $\mathrm{p} 54$ genes: Krasnodar 2008 - JQ771683.1, Elbrus 2008 JQ771682.1, Stavropol 2008 - JQ771686.1, Orenburg 2009 JQ771684.1, Rostov 2009 - JQ771685.1 and Armen ia 2007 JQ771681.1, p 22 genes: Krasnodar 2008 - JQ771689.1, Elbrus 2008 - JQ771688.1, Stavropol 2008 - JQ771692.1, Orenburg 2009 - JQ771690.1, Rostov 2009 - JQ771691.1 and Armenia 2007 - JQ771687.1 and p 12 genes: Elbrus 2008 - JQ771677.1, Stavropol 2008 - JQ771679.1, Orenburg 2009 - JQ771678.1, Volgograd 2010 - JQ771680.1 and Armenia 2007 - JQ771676.1.

\section{ACKNOWLEDGEMENTS}

We express our gratitude to Yu.F.Kalantaenko and A.S. Malogolovkin courteous help on this project. 
We thank prof. Yu.O.Selyaninov and I.S Schelkunov for helpful comments on the manuscript. Special thanks for A.V.Lunitsin for support of this project.

\section{REFERENCES}

[1] Linda K. Dixon, Joao V. Costa, Jose M. Escribano, Daniel L. Rock, Eladio Vinuela, Philip J. Wilkinson, Family Asfarviridae, Virus taxonomy: classification and nomenclature of viruses, Seventh report of the International Committee on Taxonomy of Viruses, Edided: M.H.V. van Regenmortel, C.M. Fanquet, D.H.L. Bishop, E.B. Carstens, M.K. Estes, S.M. Lemon, J. Maniloff, M.A. Mayo, D.L. MoGeohh, C.R. Pringle, R.B. Wickner (eds), Academic press: San Diego, pp. $159-165,2000$

[2] Steven B. Kleiboeker, Thomas G. Burrage, Glen A. Scoles, Durland Fish, Daniel L. Rock, "African Swine Fever Virus Infection in the Argasid Host, Ornithodoros porcinus porcinus", Journal of Virology, vol.72, no.3, pp.1711-1724, 1998.

[3] Jose L. Carrascosa, Jose Maria Carazo, Angel L. Carrascosa, Norma Garcia, Arantza Santisteban, Eladio Vinuela, "General morphology and capsid fine structure of African swine fever virus particles", Virology, vol.132, no.1, pp.160-172, 1984.

[4] Zilda G. Carvalho, A.P.Alves De Matos, Claudina Rodrigues-Pousada, "Association of African swine fever virus with the cy toskeleton", Virus Research, vol.11, no.2, pp.175-192, 1988.

[5] Enrique Tabares, M. A. Marcotegui, M. Fernandez, C. Sanchez-Botija, "Proteins specified by African swine fever virus. I. Analysis of viral structural proteins and antigenic properties". Archives Virology, vol.66, no.2, pp.107-117, 1980.

[6] Rafael J. Yanez, Javier M. Rodriguez, Maria L. Nogal, Luis Yuste, Carlos Enríquez, Jose F. Rodriguez, Eladio Vinuela, "Analysis of the complete nucleotide sequence of African swine fever virus", Virology, vol.208, no.1, pp.249-278, 1995.

[7] Angel L. Carrascosa, Isabel Sastre, Eladio Vinuela, "African Swine Fever Virus Attachment Protein", Journal of Virology, vol.65, no.5, pp.2283-2289, 1991.

[8] Fernando Rodriguez, Victoria Ley, Paulino Gomez-Puertas, Ramon Garcia, Jose F. Rodriguez, Jose M. Escribano, "The structural protein p54 is essential for African swine fever virus viability", Virus Research, vol.40, no.2, pp.161-167, 1996.

[9] Javier M. Rodriguez, Ramon Garcia-Escudero, Maria L. Salas, German Andres, "African Swine Fever Virus Structural Protein p54 Is Essential for the Recruitment of Envelope Precursors to Assembly Sites", Journal of Virology, vol.78, no.8, pp.4299-4313, 2004.

[10] Claudio L. Afonso, Carlos Alcaraz, Alejandro Brun, Michael D. Sussman, Dale V. Onisk, Jose M. Escribano, Daniel L. Rock, "Characterization of p 30, a highly antigen ic membrane and secreted protein of African swine fever virus", Virology, vol.189, no.1, pp.368-373, 1992.

[11] Paulino Gomez-Puertas, Fernando Rodriguez, Jose M. Oviedo, Fernando Ramiro-Ibanez, Francisco Ruiz-Gonzalvo, Covadonga Alonso, Jose M. Escribano, "Neutralizing Anti- bodies to Different Proteins of African Swine Fever Virus Inhibit Both Virus Attachment and Internalization", Journal of Virology, vol.70, no.8, pp.5689-5694, 1996.

[12] Ana Camacho, Eladio Vinuela, "Protein p 22 of African Swine Fever Virus: An Early Structural Protein That Is Incorporated into theM embrane of Infected Cells", Virology, vol.181, no.1, pp.251-257, 1991.

[13] Fernando Almazan, Javier M. Rodriguez, Ana Angu lo, Eladio Vinuela, Jose F. Rodriguez, "Transcriptional Mapping of a Late Gene Coding for the p 12 Attachment Protein of African Swine Fever Virus", Journal of Virology, vol.67, no.1, pp.553-556, 1993.

[14] Ana Angulo, Eladio Vinuela, Antonio Alcami, "Comparison of the Sequence of the Gene Encoding the African Swine Fever Virus Attachment Protein $\mathrm{p} 12$ from Field Virus Isolates and Viruses Passaged in Tissue Culture", Journal of Virology, vol.66, no.6, pp.3869-3872, 1992.

[15] M. Luisa Valdeira, Armando Geraldes, "Morphological study on the entry of African swine fever virus into cells", Biological Cell, vol.55, no.1-2, pp.35-40, 1985.

[16] Winston A. Malmquist, D. Hay, "Hemadsorption and cytopathic effect produced by African swine fever virus in swine bone marrow and buffy coat cultures", American Journal of Veterinary Researches, vol.21, no.1, pp.104-108, 1960.

[17] John G. Neilan, Laszlo Zsak, Zhiqiang Lu, Thomas G. Burrage, Gerald F. Kutish, Daniel L. Rock, "Neutralizing antibodies to African swine fever virus proteins $\mathrm{p} 30, \mathrm{p} 54$, and $\mathrm{p} 72$ are not sufficient for antibody-mediated protection", Virology, vol.319, no.2, pp.337-42, 2004.

[18] Tom Maniatis, Edward F. Fritsch, S. Sambrooks, Molecular Cloning: A laboratory Manual, Cold Spring Harbor Laboratory, USA, New York, 2006.

[19] F. Sanger, Alan R. Coulson, "A rapid method for determining sequences in DNA by primed synthesis with DNA polymerase", Journal of Molecular Biology, vol.94, no.3, pp.441-448, 1975.

[20] Thomas P. Hopp, Kenneth R. Woods, "Prediction of protein antigenic determinants from amino acid sequences", Procedia National Academical Sciences U.S.A., vol.78, no.6, pp.3824-3828, 1981.

[21] Sudhir Kumar, Koichiro Tamura, Masatoshi Nei, MEGA3: Integrated Software for Molecular Evolutionary Genetics Analysis and Sequence Alignment, Briefings in Bioinformatics, vol.5, no.2, pp.150-163, 2004.

[22] E.R. Tulman, Gustavo A. Delhon, B.K. Ku, Daniel L. Rock "African swine fever virus".Curr Top Microbiol Immunol., vol.328, pp.43-87, 2009.

[23] Pen C. Kay-Jackson, Lynnette C. Goatley, L. Cox, J. E. Miskin, R. M. E. Parkhouse, J. Wienands, Linda K. Dixon, "The CD2vprotein of African swine fever virus interacts with the actin-binding adaptor protein SH3P7", Journal of General Virology vol.85, pp. 119-130, 2004.

[24] Natalia N Vlasova, Vladimir M. Baly shev, Anna S Kazakova, "Perspective of using the recombinant DNA-technology to control the spread of the African swine fever", Procedia in Vaccinology, vol.4, pp.92-99, 2011.

[25] Linda K. Dixon, Christine Bristow, Philip J. Wilkinson, Keith J. Sumption, "Identification of a variable region of the Afri- 
can swine fever virus genome that has undergone separate DNA rearrangements leading to expansion of minisatellite-like sequences", Journal of Molecular Biology, vol.216, no.3, pp.677-688, 1990.

[26] Rafael Blasco, Montserrat Aguero, Jose M. Almendral, Eladio Vinuela, "Variable and constant regions in African swine fever virus DNA", Virology, vol.168a, no.2, pp.330-338, 1989.

[27] Keith J. Sumption, Geoffrey H. Hutchings, Philip J. Wilkinson, Linda K. Dixon, "Variable regions on the genome of Malawi isolates of African swine fever virus", Journal of General Virology, vol.71, no.10, pp.2331-2340, 1990.

[28] Enrique Tabares, Isabel Olivares, G. Santurde, Maria Jose Garcia, Elisabeth Martin, M. E. Carnero, "African swine fever virus DNA: deletions and additions during adaptation to growth in monkey kidney cells", Archiv es of Virology, vol.97, no.3-4, pp.333-346, 1987.

[29] Daniel L. Rock, "Prospects for Development of an African Swine Fever Vaccine", Oral presentation, Pokrov, Russia, 2010.

[30] Antonio Alcami, Ana Angulo, Carlos Lopez-Otin, Maribel Munoz, Jose M.P. Freije, Angel L. Carrascosa, Eladio Vinuela, "Amino Acid Sequence and Structural Properties of Protein $\mathrm{p} 12$, an African Swine Fever Virus Attachment Protein", Journal of Virology, vol.66, no.6, pp.3860-3868, 1992.

[31] Fernando Rodriguez, Carlos Alcaraz, Adolfo Eiras, Rafael J. Yanez, Javier M. Rodrguez, Covadonga Alonso, Jose F. Rodriguez, And Jose M. Escribano, "Characterization and Molecular Basis of Heterogeneity of The African Swine Fever Virus Envelope Protein p54." J. Virology, 68, no.11, pp.7244-7252, 1994

[32] Gunnar von Heijne, "Signal sequences. The limits of variation", Journal of Molecular Biology, vol.184, no.1, pp.99-105, 1985.

[33] Fernando S. Boinas, Anthony J. Wilson, Geoff H. Hutchings, Carlos Martins, Linda J. Dixon "The Persistence of African Swine Fever Virus in Field-Infected Ornithodoros erraticus during the ASF Endemic Period in Portugal", 2011 PLoS ONE 6(5): e20383. doi:10.1371/journal.pone.0020383.

[34] Armanda D. S. Bastos, Mary-Louise Penrith, Catherine Cruciere, J. L.Edrich, Geoff Hutchings, Francois Roger, Emmanuel Couacy-Hymann, Gavin R. Thomson, "Genotyping field strains of African swine fever virus by partial $\mathrm{p} 72$ gene characterization", Archives of Virology, vol.148, no.4, pp.693-706, 2003.
[35] C. I. Boshoff, Armanda D. S. Bastos, L. J. Gerber, Wilna Vosloo, "Genetic characterization of African swine fever viruses from outbreaks in southern Africa (1973-1999)", Veterinary Microbiology, vol.121, no.1-2, pp.45-55, 2007.

[36] Aleksandr Malogolovkin, Aleksandra Yelsukova, Carmina Gallardo, Sodnom Tsybanov, Denis Kolbasov, "Molecular characterization of African swine fever virus isolates originating from outbreaks in the Russian Federation between 2007 and 2011".Vet Microbiol. 2012 Mar 8.[Epub ahead of print]

[37] Vladimir M. Balyshev, Andrey V. Knize, "Geography of ASF and serotype heterogeneity of causative agent of a disease". Materials of Conference Moscow veterinary Academy. Moscow: MVA; pp.92-94, 1999.

[38] Nikifor I. Mitin, Ivan F. Vishnyakov, Jury I. Petrov, Aleksandr V. Kiselyov, Lev L. Cheryatnikov Valentin A. Burlakov VA. The seroimmunological classification of natural African swine fever virus isolates. Materials of Science -practical Conference Of VNIIVViM, Pokrov: VNIIVViM; pp.141-143, 1995.

[39] Ana Angulo, Eladio Vinuela, Antonio Alcami, "Inhibition of African Swine Fever Virus Binding and Infectivity by Purified Recombinant Virus Attachment Protein p 12", Journal of Virology, vol.67, no.9, pp.5463-5471, 1993.

[40] Rebecca J. Rowlands, Vincent Michaud, Livio Heath, Geoffrey Hutchings, Chris Oura, Wilna Vosloo, Rahana Dwarka, Tinatin Onashvili, Emmanuel Albina, Linda K. Dixon, "African swine fever virus isolate, Georgia, 2007", Emerging Infectious Diseases, vol.14, no.12, pp.1870-1874, 2008.

[41] Etienne P. de Villiers, Carmina Gallardo, Marisa Arias, Melissa da Silva, Chris Upton, Raquel Martin, Richard P. Bishop, "Phylogenomic analysis of 11 complete African swine fever virus genome sequences", Virology, vol.400, no.1, pp.128-136, 2010.

[42] Carmina Gallardo, Edward Okoth, Virginia Pelayo, Raquel Anchuelo, Elena Martın, Alicia Simon, Alicia Llorente, Raquel Nieto, Alejandro Soler, Raquel Martin, Marisa Arias, Richard P. Bishop, "African swine fever viruses with two different genotypes, both of which occur in domestic pigs, are associated with ticks and adult warthogs, respectively, at a single geo graphical site", Journal of General Virology, vol.92, no.2, pp.432-444, 2011. 